\title{
Prevalence and Pattern of Tobacco Usage Among Children Aged 9 to 13 Years in Schools of Naswadi Village, Gujarat, India
}

\author{
${ }^{1}$ Bhavna H Dave , ${ }^{2}$ Princy S Thomas, ${ }^{3}$ Kruti R Jhaveri , ${ }^{4}$ Hirva P Jhala
}

\begin{abstract}
Introduction: Tobacco use among children is ever increasing especially in rural parts of the country. Knowledge about its prevalence and usage pattern among children may aid in adopting measures for awareness and prevention of its use among children.
\end{abstract}

Aim: To evaluate the prevalence and pattern of tobacco usage among children aged 9 to 13 years in Schools of Naswadi village, Gujarat, India.

Method: A cross-sectional questionnaire-based study was conducted in two schools of Naswadi village among 252 children. The participants were asked to complete a questionnaire and the forms were collected on the same day. The questionnaire was comprised of sociodemographic characteristics such as age, gender, grade, etc. and tobacco consumption habit was assessed in detail such as the type of tobacco used, mode of consumption, duration of tobacco use, reasons for use, etc. All the data obtained was analyzed, and the Chi-square test was used $(p<0.001)$.

Results: The overall prevalence observed was 53.2\%. Out of 252 participants, 134 were using tobacco products. The overall prevalence among boys was $62.7 \%$ and among girls was $43.7 \%$. About $88.5 \%$ of the boys and $100 \%$ of the girls consumed the smokeless type of tobacco. Majority of the children, $43 \%$ boys and $53 \%$ of girls started the habit as early as 9 to 10 years of age. Majority of the children (73.9\%) procured tobacco from a family member $(p<0.001)$.

Conclusion: A high prevalence of tobacco use among children was observed in the present study. The age of initiation of the habit was found to be as early as 9 to 10 years of age. Majority of the children obtained a tobacco product from a family member.

Keywords: Gujarat, Questionnaire-based study, School-going children, Tobacco use.

How to cite: Dave BH, Thomas PS, Jhaveri KR, Jhala HP. Prevalence and Pattern of Tobacco Usage Among Children Aged 9 to13 Years in Schools of Naswadi Village, Gujarat, India. J Oral Health Comm Dent 2018;12(3):73-78.

\footnotetext{
${ }^{1}$ Professor and Head, ${ }^{2}$ Postgraduate Student, ${ }^{3,4}$ Intern

${ }^{1-4}$ Department of Pedodontics and Preventive Dentistry, KM Shah Dental College and Hospital, Vadodara, Gujarat, India

Corresponding Author: Bhavna H Dave, Professor and Head, Department of Pedodontics and Preventive Dentistry, KM Shah Dental College and Hospital, Vadodara, Gujarat, India, e-mail: bhavnadave1964@gmail.com
}

\author{
Source of support: Nil \\ Conflict of interest: None
}

\section{INTRODUCTION}

The use of tobacco has always been a hindering factor in a developing nation like India and chewing tobacco apparently is extensively prevailing in Gujarat. ${ }^{1}$ Tobacco use is a leading cause of avertable fatality world over, more so in developing nations. According to the World Health Organization (WHO), addiction to tobacco claims one life prematurely every 6 seconds. ${ }^{2}$ In India alone, approximately one in every 10 children in the age range of 10 to 15 year have ever smoked cigarettes, and almost half of these children have initiated tobacco use before 10 years of age. ${ }^{3}$ The most widespread rationale reported for children to initiate using tobacco is a direct influence of peers, parental tobacco habits and pocket money given to children. ${ }^{1}$

As per India's Cigarette and Other Tobacco Product Act 2003 (COTPA), supplying or promoting tobacco to minors or supplying of tobacco by minors (under the age of 18) is lawfully prohibited and infringement of the same is a punishable offense. Same applies to supply of tobacco containing items within 100 yards radius of any educational premise. ${ }^{4}$

Despite the laws and regulations, with the change in the perception of the society and ease of accessibility the prevalence of smoking among young children has increased many folds and is at present a significant public health problem. The early age of initiation accentuates the urgent need to intervene and protect this vulnerable group from falling prey to this addiction. ${ }^{5}$

The present study was undertaken intending to provide data regarding tobacco abuse among children between 9 to 13 years of age residing in the Naswadi Village, Gujarat. The study focused on procuring data regarding the prevalence, initiation of habit, the pattern of usage and accessibility for tobacco use among the selected children.

\section{METHODOLOGY}

A cross-sectional study was conducted among school children aged 9 to 13 years from the schools of Naswadi village, Gujarat. About 252 children belonging to both 
genders were approached to participate in the study from the two schools of the village.

The study was conducted after obtaining written consent from the participant's parents a day before administering the questionnaire. A self-administered, pre-tested, structured, close-ended questionnaire was used for data collection. The questionnaire comprised information on sociodemographic characteristics such as age, gender, grade, etc. Tobacco consumption habit was assessed in detail such as the type of tobacco used, the age of initiation, the source of tobacco products, place of consumption and the desire to quit the habit. The questionnaire was in the local language-Gujarati.

Content validity of the questionnaire was done by two experts. After that, the concurrent validation of the same questionnaire was done on a pilot sample.

A detailed description of the study was given to the participants, and they were explained thoroughly about all the questions and how to fill up the questionnaire. Students who were present at the time of administration of the questionnaire and willing to participate in the study were included. The subjects were given a day to fill up the questionnaire, and the forms were collected back the same day. A second attempt was made to cover up the absentees on the next day and forms were collected the same day. The study was conducted for 3 months. The anonymity of the participants was maintained by avoiding any information revealing the identity of the participants in the questionnaire. The school teachers and parents were not interviewed regarding children's habit. At the end of the survey, the children and parents were educated regarding the hazards of tobacco consumption to discourage their habit.

Collected data were fed into an Excel spreadsheet and transferred to Statistical Package for the Social Sciences (SPSS) 17 for data management and analysis. Descriptive

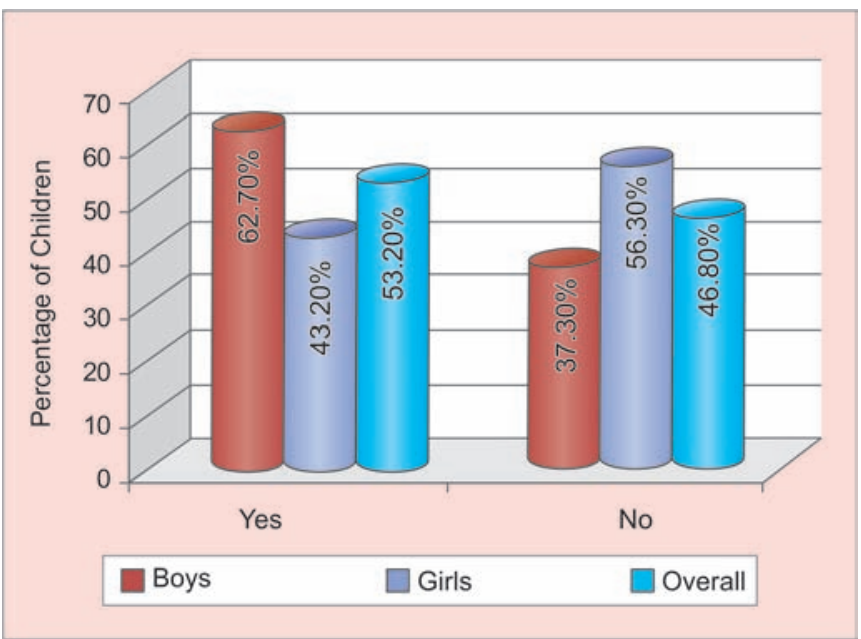

Graph 1: Prevalence of tobacco use among boys and girls statistics such as percentages and frequencies were analyzed using the Pearson's Chi-square tests to find out significant mean differences. The test was considered significant when the two-sided p-value was less than 0.001

\section{RESULTS}

A total of 252 children from all the schools of the village participated in this study. The equal number of boys and girls were included in the study. Among the children, maximum $(33.7 \%)$ participants were between 12 to 13 years of age, followed by 11 to 12 years (25\%), 10 to 11 years (21.4\%) and 9 to 10 years (19.8\%).

Out of 252 participants, 134 were using tobacco products. The overall prevalence observed was $53.2 \%$. The overall prevalence among boys was $62.7 \%$ and among girls was $43.7 \%$ (Graph 1).

Majority of the children, $43 \%$ boys and $53 \%$ of girls started the habit as early as 9 to 10 years of age (Graph 2). About $88.5 \%$ of the boys and $100 \%$ of the girls consumed the smokeless type of tobacco (Graph 3). It was found that $69.6 \%$ of the boys and $87.3 \%$ of the girls consumed tobacco on a daily basis. Majority of the children $(73.9 \%)$ procured tobacco from a family member (Graph 4). $91.1 \%$ of boys and $100 \%$ girls found no difficulty in procuring any form of tobacco. Majority of the children ( $51.9 \%$ boys and $47.3 \%$ girls) consumed either form of tobacco at home, followed by friend's home (Graph 5).

\section{DISCUSSION}

\section{Prevalence of Tobacco Use among Children}

Numerous studies have been undertaken in the past to determine the prevalence of tobacco use among school going children. In a study by Makwana et al., they reported the prevalence of tobacco chewing to be $33.12 \%$

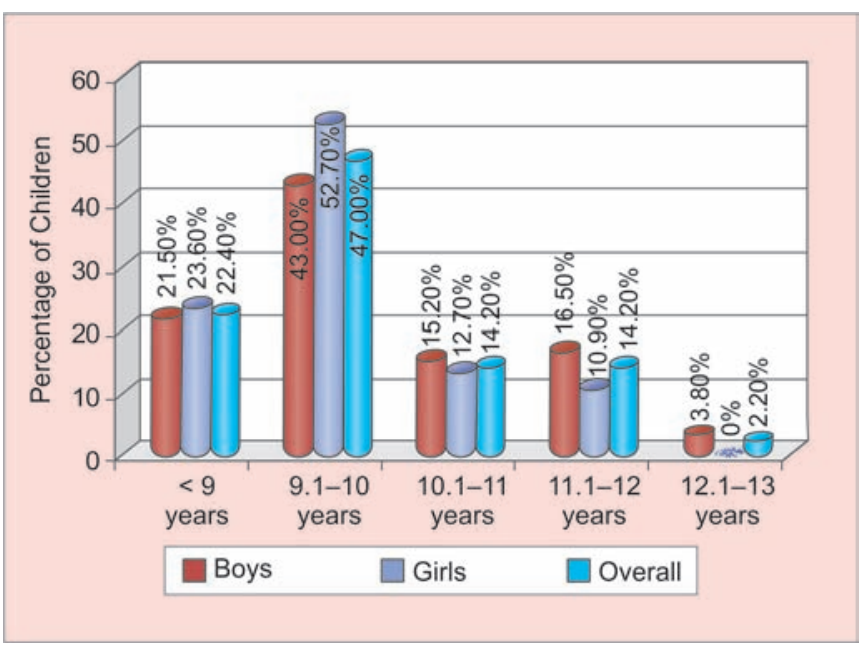

Graph 2: Age of initiation 


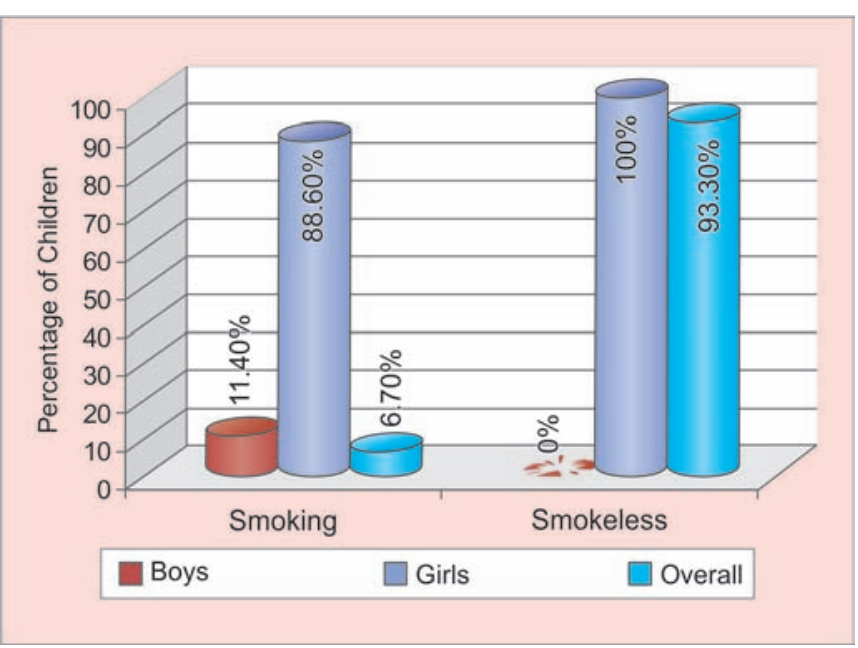

Graph 3: Type of tobacco consumed

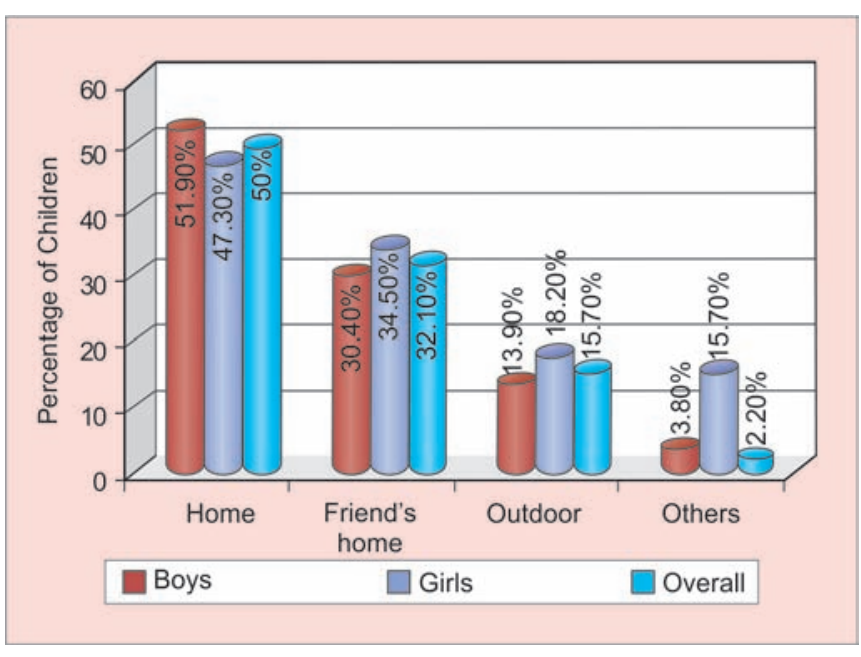

Graph 5: Place where children consumed tobacco

( $\mathrm{n}=908)$ conducted among adolescents from the rural areas of Jamnagar district. ${ }^{6}$ Jayakumary et al. reported $5.5 \%$ prevalence among 3000 adolescents in North Kerala. ${ }^{7}$ In Mathura city, Chaudhary et al. reported the prevalence of tobacco use among college students aged 15 - 30 years to be of $40 \% .^{8}$ A recent study by Jaisoorya et al. conducted in Kerala among 7350 adolescents, a prevalence of $6.9 \%$ was reported. ${ }^{9}$

The present study reports an overall prevalence of $53.2 \%$ on a smaller sample of 252 children using tobacco products in any form. The prevalence reported in our study is much higher compared to the other studies. This could be due to the following reasons: evaluation of a smaller sample size and the lack of awareness in the Naswadi village owing to the varying social, economic and cultural characteristics and lack of implementation and effectiveness of the anti-tobacco policies in remote rural villages.

\section{Gender Distribution}

The use of tobacco was found to be higher in boys (62.7\%) as compared to girls (43.7\%). Jayakumary et al. reported

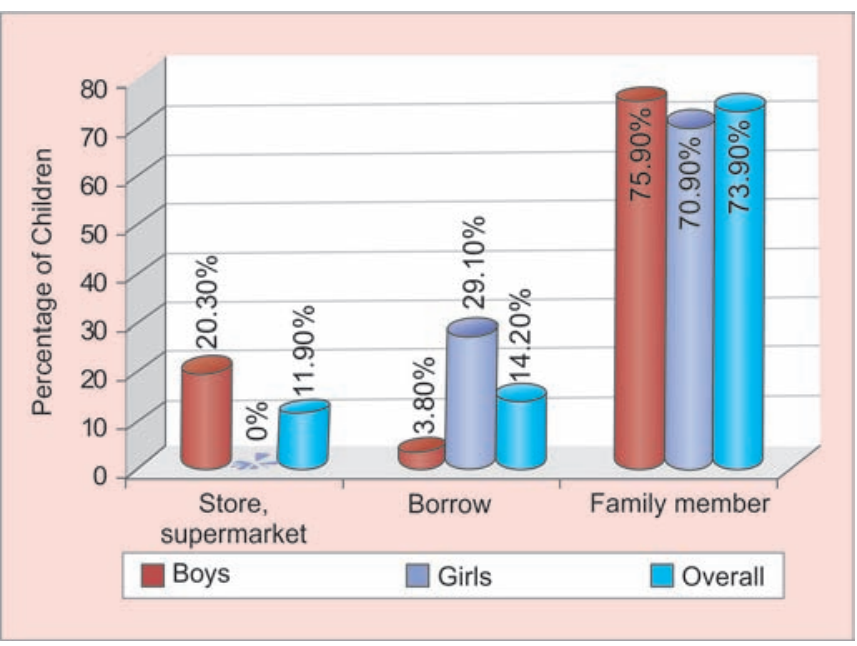

Graph 4: Source of tobacco products

high rates of oral tobacco use among boys (57\%) and girls $(41 \%){ }^{7}$ Kumar et al. reported a prevalence of ever tobacco users among school children of Chennai city as $41.6 \%$ among boys and $30.2 \%$ among girls. ${ }^{10}$ Thus, the present finding was in accordance with the other studies, which have reported a general male predominance for tobacco use.

Despite the male predominance observed in this study, it was found that all of the females, who used tobacco, consumed it on a daily basis and found no difficulty in procuring the same. This observation was against the usual social norms of a society.

\section{Age of Onset}

Numerous studies conducted in India have reported the age of onset for the use of tobacco to vary between 8 to 15 years. Ahmed et al. reported the age of initiation for tobacco use as early as 10 years. ${ }^{11}$ In the study conducted by Narain et al. the age at initiation of tobacco use reported among the adolescents was $12.6 \pm 2$ years, and it was not significantly different between the genders. ${ }^{3}$ These findings were in accordance with the present study, where the reported age of onset for tobacco use among boys and girls was similar and found to be 9 to 10 years.

The age of initiation of tobacco-related habits is important because the earlier the children start using it, the more likely they are to continue the habit and become addicts, which will place a high disease burden on the society. ${ }^{12}$

\section{Pattern of Tobacco Use}

Tobacco consumption in India is prevalent in varied forms, and it presents an increasing threat to the health of children and adolescents. Many factors contribute to the initiation, experimentation and regular use of tobacco among children. Major determinants for tobacco use among children are: exposure to parental, sibling and peer 
smoking; peer group pressure; easy access to smoking and non-smoking forms of tobacco; aggressive promotion and advertising; low cost, etc. ${ }^{13}$ Thus the pattern of tobacco use among children more or less depends on the underlying determinants for the habit.

\section{Type of Tobacco Consumed}

The present study revealed that about $93.3 \%$ of the participants consumed the smokeless variety of tobacco preferably tobacco chewing as compared to smoking tobacco (Figs 1 and 2). Similar findings were reported by Makwana et al., where the increased tendency of chewing tobacco $(66.23 \%)$ among 17 to 19 years old adolescents was observed. ${ }^{6}$

India being a land of cultures and tradition, joint family smoking is a taboo in Indian families. Primarily, smoking of tobacco was restricted to only the dominant male members of the family. Although smoking tobacco was a taboo, smokeless forms of tobacco were widely accepted. ${ }^{13}$ This may be one of the reasons for the increased consumption of a smokeless variety of tobacco among children.

According to a study conducted by Gupta et al.,14 they stated that another major reason that encourages children/caregivers to use smokeless form of tobacco are its low price, ease of purchase or production, and the widely held misconception that it has medicinal value for improvement in toothache, headache, and stomach ache. Furthermore, the government's efforts have also focused more on eliminating cigarette use than tobacco as a whole. ${ }^{14,15}$

Smokeless variety of tobacco is mainly available in two forms: chewing tobacco and snuff (moist or dry). Chewing tobacco is used orally by placing a pinch between the gum and cheek and gently sucking and chewing.

The active ingredient in any form of tobacco for addiction is a naturally occurring drug, and nicotine. ${ }^{2}$

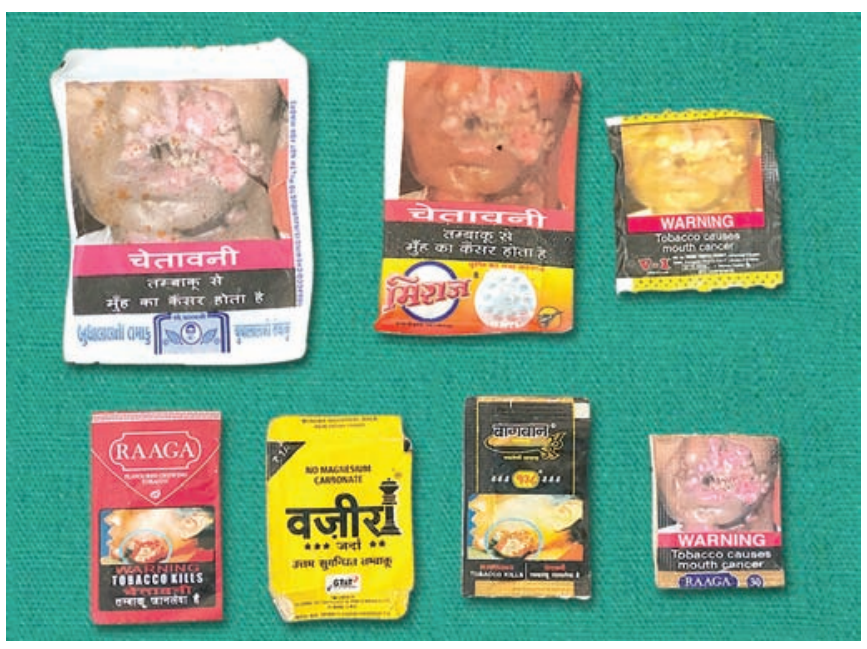

Fig. 1: Smokeless form of tobacco products
Smokeless tobacco products differ significantly in nicotine content, $\mathrm{pH}$, and levels of various carcinogens. Since nicotine is absorbed through the buccal mucosa, its uptake is affected by both the $\mathrm{pH}$ of the tobacco product and the $\mathrm{pH}$ of the mouth. The rate of absorption and action for nicotine from smokeless tobacco is thus slower than that from tobacco that enters the body via the lungs when smoked. The delayed effect may make smokeless products less addictive than smoking type. However, it is observed that smokeless tobacco users report that quitting cigarettes is easier than quitting smokeless tobacco. ${ }^{2}$

Nicotine is known to affect metabolism by decreasing appetite and increasing metabolic rate. ${ }^{2}$ This characteristic feature probably could be a yet another factor for introducing tobacco among young children from rural areas having low socioeconomic status. As chewing tobacco decreases the hunger pangs in children, and thus the burden of feeding the children is reduced considerably.

Thus it may be concluded that all the above-mentioned factors along with peer pressure and belief that using smokeless tobacco is less hazardous than smoking mean that these forms continue to be used by vast numbers of people, especially children. ${ }^{15}$

\section{Source of Tobacco Products}

The findings of our study showed that majority of the children, both boys and girls (73\%) procured tobacco from a family member; while $20.3 \%$ boys obtained it from local stores or vendors and $29.1 \%$ girls borrowed it from someone. These findings displayed that parents/ caregiver or family members encouraged or were aware of their child's habit. As stated earlier, nicotine is known to reduce appetite which could be a major reason for the encouragement of tobacco usage among children by family members. The present study did not interview parents/caregivers/family members regarding their knowledge about the child's habit or their habit.

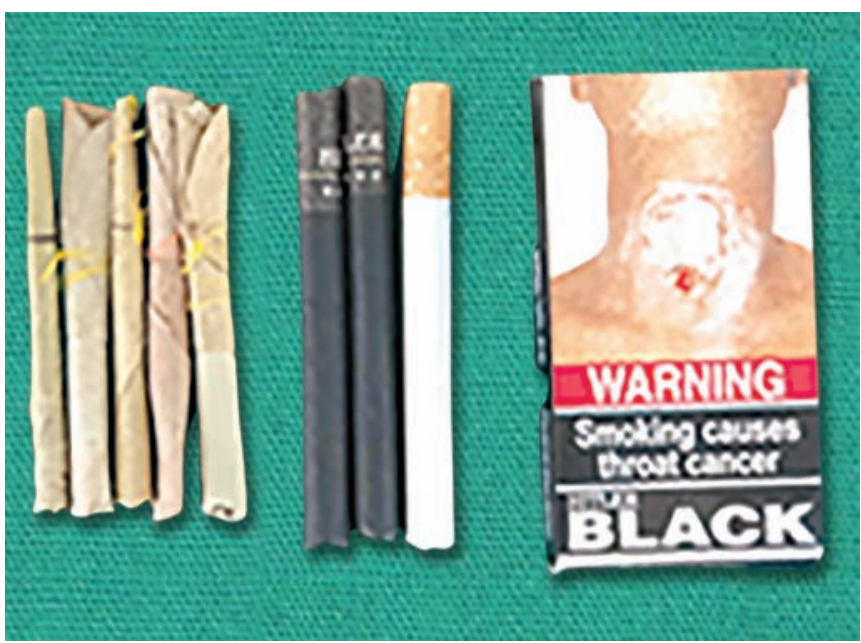

Fig. 2: Smoking form of tobacco products 
Despite the law against selling tobacco products to minors, children in India face no problem in procuring it from local vendors. Also in India, many at times, a family member asks their children to fetch tobacco products such as beedis or cigarettes from nearby stores. In this way, children are often introduced to such products at their very early life stages. A child growing in such a family watching his elder brother/sister, father/mother, other family members using tobacco may perceive it as a family tradition that is to be followed. On the contrary, in Indian custom, a child smoking in the presence of an elderly is scorned upon; whereas chewing smokeless tobacco holds no such restriction. ${ }^{16}$

In a study by Dwivedi et al., $45.5 \%$ of the patients were tobacco users, and $81 \%$ of those who were using tobacco had a positive family history. ${ }^{17}$ The finding highlighted an important fact that the habit of tobacco use runs in families. However, in the present study, the family history for tobacco use was not evaluated. But the fact that children obtained the product from a family member may indicate a positive family history.

These findings beckon the need to target anti-tobacco messages and awareness among family members and society as well as among children.

\section{Place of Consumption}

The majority of the participants in the present study were found to consume tobacco at their home (boys-51.9\% and girls- $-47.3 \%$ ) at friend's home (boys- $30.4 \%$ and girls-34.5\%) and outdoor and other places. This finding supports our belief that the habit may have initiated at home and encouraged by family members.

\section{Quitting the Habit}

The ideal approach to decrease the adverse effects caused by tobacco is to quit the habit. However, not all tobaccousers are prepared to quit. The present study reported only about $20.1 \%$ participants who displayed a desire to discontinue the habit. With a notion to discourage the tobacco use, the participants and their parents were educated about the hazards of tobacco use at the end of the survey.

\section{LIMITATIONS}

The sample size included in the present study was limited as the study was conducted in schools of Naswadi village which comprises of only two schools. Also, the family history was not taken into consideration, as the survey was limited to just the children and not their family members. Another limitation was that family members and teachers were not interviewed regarding their awareness about the children's habit. Further, the participants were not examined for any adverse effects of the habit.

\section{CONCLUSION}

In conclusion, the present study reported an overall prevalence of $53.2 \%$ of tobacco usage in either smoking or smokeless form. The influence by family members was the reason for initiating this habit in the majority of the users. The present study thus suggests the need for school-based tobacco prevention programs and educative programs for the parents/caregivers as it is better to prevent the initiation of the habit than trying to stop the habit, thus emphasizing the role of primary prevention.

The present study provided a baseline data about a crucial problem prevailing in a small geographical area. The present issue should be addressed at a larger level emphasizing on interventions to curb the hazardous habit among children. Further research with larger samples should be undertaken, keeping in mind the above limitations, to evaluate and create awareness regarding the hazards of tobacco usage among children in the rural setup.

\section{REFERENCES}

1. Walsh P. The Oral Effects of Smokeless Tobacco. J Can Dent Assoc. 2000; 66:22-25.

2. Samet JM, Yoon SY, World Health Organization. Gender, women, and the tobacco epidemic 2010.

3. Narain R, Sardana S, Gupta S, Sehgal A. Age at initiation \& prevalence of tobacco use among school children in Noida, India: A cross-sectional questionnaire based survey. The Indian journal of medical research. 2011 Mar;133(3):300.

4. Naik S, Patil S, Kamble S, Khan M. Awareness about Tobacco habit, its hazards and willingness to quit the habit among patients. J Med Dental Sci. 2013;3:27-31.

5. Joshi U, Modi B, Yadav S. A Study on Prevalence of Chewing Form of Tobacco and Existing Quitting Patterns in Urban Population of Jamnagar, Gujarat. Indian J Community Med. Jan 2010; 35(1): 105-108.

6. Makwana NR, Shah VR, Yadav S. A study on prevalence of smoking and tobacco chewing among adolescents in rural areas of Jamnagar district, Gujarat state. JMSR. 2007 Sep 30;1(1):47-50.

7. Muttappallymyalil J, Divakaran B, Thomas T, Sreedharan J, Haran JC, Thanzeel M. Prevalence of tobacco use among adolescents in north Kerala, India. Asian Pacific Journal of Cancer Prevention. 2012;13(11):5371-5374.

8. Chaudhary A, Ingle NA, Dhanker K, Kaur N. Prevalence of Tobacco use Among the Students in Professional and Non-Professional Colleges of Mathura City. Journal of Oral Health \& Community Dentistry. 2014 Jan 1;8(1).

9. Jaisoorya TS, Beena KV, Beena M, Jose DC, Ellangovan K, Thennarasu K, Benegal V. Prevalence \& correlates of tobacco use among adolescents in Kerala, India. The Indian journal of medical research. 2016 Nov;144(5):704.

10. Kumar PM, Poorni S, Ramachandran S. Tobacco use among school children in Chennai city, India. Indian journal of cancer. 2006 Jul 1;43(3):127. 
11. Ahmed NU, Ahmed NS, Semenya KA, Elzey JD, Larson C, Bennett CR, Hinds JE. Prevalence and correlates of initiation of smoking behavior among preteen black and white children. Journal of the National Medical Association. 2004 Feb;96(2):200.

12. Saji AE, Jain R, Pabla A. Tobacco use among teenagers in Ludhiana, Punjab, India: A survey of initiation, prevalence, knowledge, and attitude. CHRISMED Journal of Health and Research. 2014 Jul 1;1(3):176.

13. Preeti S, Raut DK. Prevalence and pattern of tobacco consumption in India. International research journal of social sciences. 2012;1(4):36-43.
14. Gupta PC, Ray CS. Smokeless tobacco and health in India and South Asia. Respirology 2003;8:419-31.

15. Muttapppallymyalil J, Sreedharan J, Divakaran B. Smokeless tobacco consumption among school children. Indian journal of cancer. 2010 Jul 1;47(5):19.

16. Chadda RK, Sengupta SN. Tobacco use by Indian adolescents. Tobacco induced diseases. 2002 Jun 15;1(2):111.

17. Dwivedi S, Pathak R, Agarwalla R, Ali W. The intergenerational transmission of tobacco habit: Role of parents and the family. Journal of family medicine and primary care. 2016 Apr;5(2):373 